\title{
Robust $\mathrm{H}_{\infty}$ Controller in a MRF Engine Mount for Improving the Vehicle Ride Comfort
}

\author{
Seyed Salman Hosseini \\ School of Automotive Engineering, Iran University of Science and Technology, Tehran, Iran. \\ Javad Marzbanrad ${ }^{\dagger}$ \\ Faculty at School of Automotive Engineering, Iran University of Science and Technology, Tehran, Iran. \\ $\dagger$ Corresponding author
}

\begin{abstract}
(Received 12 January 2019; accepted 2 August 2019)
In this paper, a robust controller is designed with the help of a Magnetorheological fluid (MRF) for a semi-active engine mount. To do so, an 8-DOF vehicle model is chosen in which the road roughness and engine vibration are the disturbance inputs to the system and the mass of the vehicle is taken into accounts as an uncertainty. In addition, the maximum magnitude and frequency of the force applied to the vehicle body by the actuators are limited in the ranges of $0 \sim 1500 \mathrm{~N}$ and $0 \sim 10 \mathrm{~Hz}$, respectively. To validate such a design, the proposed controller is compared with a PID controller. The comparison results show that the proposed controller has a good performance while dealing with uncertainties such a way that using it leads to transmitting the engine vibration frequency less than $6 \%$. It is also shown that the vibrations due to disturbances entering the system are effectively reduced in the system including the proposed controller.
\end{abstract}

\section{INTRODUCTION}

Recently, the use of Magnetorheological (MR) engine mounts for improving Noise, Vibration and Harshness (NVH) performance has been increasing due to their interesting properties. These properties result from the use of a smart Magnetorheological Fluid (MRF), which has an ability to respond quickly to the applied magnetic field in a range of frequencies. Engine idle vibrations and uneven road-induced vibrations are usually below $50 \mathrm{~Hz}$. The frequency of the driving engine vibrations is usually between 50 and $200 \mathrm{~Hz}$ with its vibration magnitude being less the $3.0 \mathrm{~mm}{ }^{1}$ An engine mount is thus required to be designed in such a way that the mentioned vibrations are properly damped at both frequency ranges. ${ }^{2}$ The first evaluation of the MR engine mounts performance by replacing the hydraulic fluid within the engine mount with MR fluid is done. The MR fluid flows within the chambers of the engine mount and leads to reduced transmission of engine vibrations to the body through changing engine mount stiffness in the driving engine vibrations., ${ }^{3,4}$ By comparing the characteristics of an ideal engine mount with those of a typical elastomeric engine mount and smart engine mounts containing MR fluid, Sarkar et.al ${ }^{5}$ found that the mentioned smart engine mounts and ideal engine mount have a similar performance. In references, ${ }^{6-8}$ increasing the MRF stiffness through the enhancement intensity of the magnetic field applied to the fluid reduces the transmission of engine vibrations to the vehicle body. However, the mentioned references have been only characterized the mount properties without using any controller. An engine mount has been designed based on the flow mode in references. ${ }^{9}$ As described in which, the dimensions of an engine mount are specified by determining the damping force and yield stress of the LORD Corporation's Magnetorheological Fluid (MRF 132 LD) for obtaining an optimal vibration isolation. However, such a structure has not been used for any car application.
Since the reduction of the road roughness impact is important for improving vehicle ride comfort, it must also be modeled and considered in the controller design. In order to improve the vehicle, ride comfort, a random road profile used for the design of MR damper in references. ${ }^{10,11}$ The stability of control systems is also an important issue. Since the major part of the instability is due to the existence of noises and uncertainties, an efficient technique must be required in the design approach to reduce the potential errors and disturbance effects. In references, ${ }^{12}$ several control strategies that use MNF are described. These strategies include Skyhook controller, PID controller, LQG, Sliding Mode controller and $H_{\infty}$ controller. The advantages and disadvantages of each method have been pointed out. It was finally shown that the $H_{\infty}$ controller has a good role in achieving stabilization with guaranteed performance of the system. In references, ${ }^{13-15}$ suspension systems in combination with an $H_{\infty}$ have been designed to improve vehicle performance. The control targets car body, travel, and suspension deflection are stabilized in a short amount of time in comparison with passive suspension. The sensitivity analysis has been shown that the active suspension system is able to work when sprung mass changes, which may occur when passengers are added. In references ${ }^{16}$ a robust Model Reference Adaptive Controller (robust MRAC) has been employed for an active engine mount. In which, the $H_{\infty}$ control scheme and an adaptive one (MRAC) are combined for controlling the mount. Simulation results show that robust MRAC is effective in reducing the transmitted force from the engine to the chassis. Such active mounts can provide good vibration isolation performance. ${ }^{17-20}$ However, they have some drawbacks such as structural complexity, high energy consumption, and high cost, which lead to restricting their using in the industry. For solving the problems due to the mentioned shortcomings of the active mounts, semi-active mounts that use MR fluids are presented. ${ }^{21-24}$ It was reported that such semi-active mounts have controllable damping properties by applying the magnetic 
field. In addition, using these semi-active mounts in the engine mounting systems, the force transmissibility and vibration displacement can be controlled well. ${ }^{22,23}$ However, it is desired to combine the semi-active mount with $H_{\infty}$ controller for improving the vehicle ride comfort.

In this research, an $H_{\infty}$ controller is designated to control body vibration and reduce body displacement during vehicle motion when submitted to engine vibration and car moving on irregular roads.

\section{VEHICLE MODEL}

In order to simulate the vehicle body and engine, an 8-DOF vehicle model is employed. The degrees of freedom of the model include 4-DOF for wheels, 1-DOF for the mass-center shift, 2-DOF for the angular displacement of the vehicle mass center and 1-DOF for vertical displacement of the engine. The vehicle model is depicted in Fig. 1. Unsprung mass motion can be represented as: ${ }^{25}$

$$
\begin{aligned}
\ddot{x}_{u i}=\left(\frac{-1}{m_{u i}}\right)[- & k_{s i}\left(x_{s i}-x_{u i}\right)-c_{s i}\left(\dot{x}_{s i}-\dot{x}_{u i}\right) \\
+ & \left.k_{t i}\left(x_{u i}-x_{t i}\right)\right] ; \quad i=1,2,3,4
\end{aligned}
$$

in which, $m_{u i}$ represented sprung mass supported by each wheel, $k_{s i}$ and $c_{s i}$ represented the equivalent suspension stiffness and damping, $k_{t i}$ represented the equivalent tire stiffness, $x_{s}$ and $\dot{x}_{s}$ denoted the displacement and velocity of the junction point of the suspension line to the body, $x_{u i}$ and $\dot{x}_{u i}$ represented unsprung mass displacement and velocity and $x_{t i}$ reflected the road profile. These parameters are shown in the Table 2 in the Appendix A. The junction point motion of the suspension line to the body are as follows:

$$
x_{s i}=x_{c}+z_{s i} \theta_{s y}-y_{s i} \theta_{s z} ; \quad i=1,2,3,4 .
$$

in which, $x_{c}$ represented the vehicle center of mass displacement. $\theta_{s y}$ and $\theta_{s z}$ represented the roll and pitch motion of the vehicle body. $y_{s i}$ and $z_{s i}$ denoted the position of each suspension in $y$ and $z$ direction. Therefore, the force transmitted to the vehicle body from the suspension system was formulated as follows: $:^{25}$

$$
f_{s x i}=k_{s i}\left(x_{s i}-x_{u i}\right)+c_{s i}\left(\dot{x}_{s i}-\dot{x}_{u i}\right) ; \quad i=1,2,3,4 .
$$

The force exerted on the body from the engine was formulated as follows:

$$
f_{\text {mount }}=-k_{m r}\left(x_{e}-x_{s e}\right)-c_{m r}\left(\dot{x}_{e}-\dot{x}_{s e}\right)+f_{M R} ;
$$

in which $k_{m r}$ and $c_{m r}$ were the equivalent engine mount stiffness and damping. $x_{e}$ and $\dot{x}_{e}$ represented the displacement and velocity of the engine body in $x$ direction. $x_{s e}$ and $\dot{x}_{s e}$ were the position and velocity of the junction point of the mount vehicle body. $f_{M R}$ was the MR force generated by the Magnetorheological fluid which is described in the next section. The system dynamic equations were as follows:

$$
\ddot{x}_{c}=-\frac{1}{m_{s}}\left(f_{s x 1}+f_{s x 2}+f_{s x 3}+f_{s x 4}-f_{\text {mount }}\right)=
$$

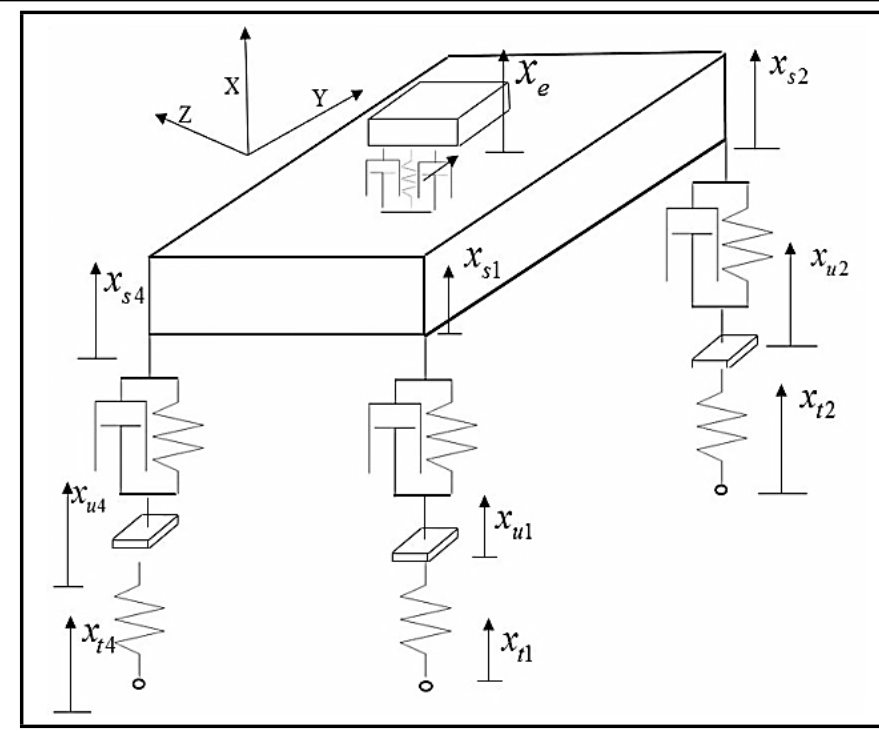

Figure 1. An 8-DOF vehicle model with the engine mount.

$$
\begin{gathered}
\left(-\frac{1}{m_{s}}\right)\left[x_{c}\left(k_{s 1}+k_{s 2}+k_{s 3}+k_{s 4}+k_{m r}\right)\right. \\
+\dot{x}_{c}\left(c_{s 1}+c_{s 2}+c_{s 3}+c_{s 4}+c_{m r}\right) \\
+\theta_{s y}\left(k_{s 1} z_{s 1}+k_{s 2} z_{s 2}+k_{s 3} z_{s 3}+k_{s 4} z_{s 4}+k_{m r} z_{m 1}\right) \\
+\dot{\theta}_{s y}\left(c_{s 1} z_{s 1}+c_{s 2} z_{s 2}+c_{s 3} z_{s 3}+c_{s 4} z_{s 4}+c_{m r} z_{m 1}\right) \\
-\theta_{s z}\left(k_{s 1} y_{s 1}+k_{s 2} y_{s 2}+k_{s 3} y_{s 3}+k_{s 4} y_{s 4}+k_{m r} y_{m 1}\right) \\
-\dot{\theta}_{s z}\left(c_{s 1} y_{s 1}+c_{s 2} y_{s 2}+c_{s 3} y_{s 3}+c_{s 4} y_{s 4}+c_{m r} y_{m 1}\right) \\
-x_{u 1} k_{s 1}-\dot{x}_{u 1} c_{s 1}-x_{u 2} k_{s 2}-\dot{x}_{u 2} c_{s 2}-x_{u 3} k_{s 3}-\dot{x}_{u 3} c_{s 3} \\
\left.-x_{u 4} k_{s 4}-\dot{x}_{u 4} c_{s 4}-k_{m r} x_{e}-c_{m r} \dot{x}_{e}-f_{M R}\right]
\end{gathered}
$$

$$
\begin{gathered}
\ddot{\theta}_{s y}=\left(\frac{-1}{i_{s y}}\right) \\
{\left[f_{s x 1} z_{s 1}+f_{s x 2} z_{s 2}+f_{s x 3} z_{s 3}+f_{s x 4} z_{s 4}-f_{m o u n t} z_{m}\right]=} \\
\left(\frac{-1}{i_{s y}}\right)\left[x_{c}\left(k_{s 1} z_{s 1}+k_{s 2} z_{s 2}+k_{s 3} z_{s 3}+k_{s 4} z_{s 4}\right)\right. \\
\quad+\dot{x}_{c}\left(c_{s 1} z_{s 1}+c_{s 2} z_{s 2}+c_{s 3} z_{s 3}+c_{s 4} z_{s 4}\right) \\
+\theta_{s y}\left(k_{s 1} z_{s 1}^{2}+k_{s 2} z_{s 2}^{2}+k_{s 3} z_{s 3}^{2}+k_{s 4} z_{s 4}^{2}\right) \\
\quad+\dot{\theta}_{s y}\left(c_{s 1} z_{s 1}^{2}+c_{s 2} z_{s 2}^{2}+c_{s 3} z_{s 3}^{2}+c_{s 4} z_{s 4}^{2}\right) \\
-\theta_{s z}\left(k_{s 1} z_{s 1} y_{s 1}+k_{s 2} z_{s 2} y_{s 2}+k_{s 3} z_{s 3} y_{s 3}+k_{s 4} z_{s 4} y_{s 4}\right) \\
-\dot{\theta}_{s z}\left(c_{s 1} z_{s 1} y_{s 1}+c_{s 2} z_{s 2} y_{s 2}+c_{s 3} z_{s 3} y_{s 3}+c_{s 4} z_{s 4} y_{s 4}\right) \\
-k_{s 1} z_{s 1} x_{u 1}-c_{s 1} z_{s 1} \dot{x}_{u 1}-k_{s 2} z_{s 2} x_{u 2}-c_{s 2} z_{s 2} \dot{x}_{u 2} \\
-k_{s 3} z_{s 3} x_{u 3}-c_{s 3} z_{s 3} \dot{x}_{u 3}-k_{s 4} z_{s 4} x_{u 4} \\
\left.-c_{s 4} z_{s 4} \dot{x}_{u 4}-f_{m o u n t} z_{m}\right] ;
\end{gathered}
$$

$$
\begin{gathered}
\ddot{\theta}_{s z}=\left(\frac{1}{i_{s z}}\right) \\
\cdot\left[f_{s x 1} z_{s 1}+f_{s x 2} z_{s 2}+f_{s x 3} z_{s 3}+f_{s x 4} z_{s 4}-f_{m o u n t} y_{m}\right] \\
=\left(\frac{1}{i_{s z}}\right)\left[x_{c}\left(k_{s 1} y_{s 1}+k_{s 2} y_{s 2}+k_{s 3} y_{s 3}+k_{s 4} y_{s 4}\right)\right. \\
\quad+\dot{x}_{c}\left(c_{s 1} y_{s 1}+c_{s 2} y_{s 2}+c_{s 3} y_{s 3}+c_{s 4} y_{s 4}\right) \\
+\theta_{s y}\left(k_{s 1} y_{s 1} z_{s 1}+k_{s 2} y_{s 2} z_{s 2}+k_{s 3} y_{s 3} z_{s 3}+k_{s 4} y_{s 4} z_{s 4}\right) \\
+\dot{\theta}_{s y}\left(c_{s 1} y_{s 1} z_{s 1}+c_{s 2} y_{s 2} z_{s 2}+c_{s 3} y_{s 3} z_{s 3}+c_{s 4} y_{s 4} z_{s 4}\right) \\
\quad-\theta_{s z}\left(k_{s 1} y_{s 1}^{2}+k_{s 2} y_{s 2}^{2}+k_{s 3} y_{s 3}^{2}+k_{s 4} y_{s 4}^{2}\right)
\end{gathered}
$$




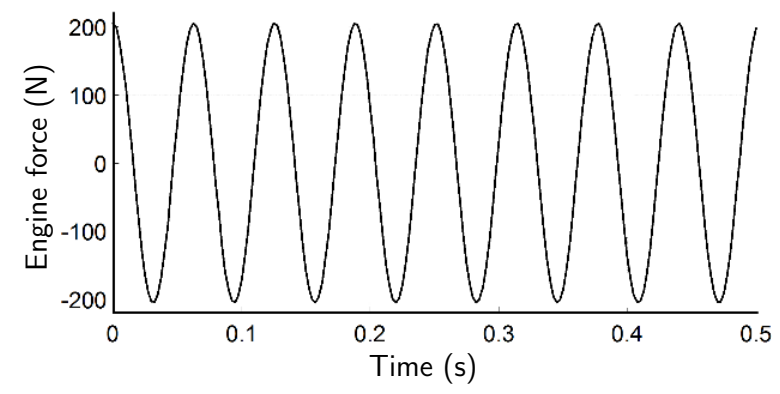

Figure 2. The vibration force applied by the engine at a frequency of $100 \mathrm{~Hz}$.

$$
\begin{gathered}
-\dot{\theta}_{s z}\left(c_{s 1} y_{s 1}^{2}+c_{s 2} y_{s 2}^{2}+c_{s 3} y_{s 3}^{2}+c_{s 4} y_{s 4}^{2}\right) \\
-k_{s 1} y_{s 1} x_{u 1}-c_{s 1} y_{s 1} \dot{x}_{u 1}-k_{s 2} y_{s 2} x_{u 2}-c_{s 2} y_{s 2} \dot{x}_{u 2}-k_{s 3} y_{s 3} x_{u 3} \\
\left.-c_{s 3} y_{s 3} \dot{x}_{u 3}-k_{s 4} y_{s 4} x_{u 4}-c_{s 4} y_{s 4} \dot{x}_{u 4}-f_{\text {mount }} y_{m}\right] ; \quad \text { (7) }
\end{gathered}
$$

where, $y_{m}$ and $z_{m}$ were the position of mount in engine body coordinate in $y$ and $z$ direction.

\subsection{Engine Mount Structure}

In order to simulate the engine mount, a 1-DOF model of conventional engine mounts with MRF was used. The intended equations for the engine mount were as follows:

$$
\begin{aligned}
& \sum f=m_{e} \ddot{x}_{e} \Rightarrow f_{e}-f_{\text {mount }}=m_{e} \ddot{x}_{e} \Rightarrow \\
& m_{e} \ddot{x}_{e}+k_{m r}\left(x_{e}-x_{s e}\right)+c_{m r}\left(\dot{x}_{e}-\dot{x}_{s e}\right)=f_{e}-f_{M R}
\end{aligned}
$$

where $m_{e}$ was the engine mass and $f_{e}$ was the unbalanced engine simulation force. $f_{e}$ and $f_{M R}$ were calculated as follows: ${ }^{26}$

$$
\begin{gathered}
f_{e}=m e \omega^{2} e^{i \omega t} \\
f_{M R}=f_{\text {yield }}
\end{gathered}
$$

where $\omega$ was the engine rotation speed, $f_{\text {yield }}$ was the magnetic force caused by the fluid and $e$ was equivalent distance of unbalance mass. Fig. 2 indicates the force exerted from the engine to the chassis at the frequency $100 \mathrm{~Hz}$.

Due to the geometry of the engine mount, the relationship between the force generated by the MRF $\left(f_{\text {yield }}\right)$ was calculated from the following equation: ${ }^{26}$

$$
\begin{aligned}
& f_{\text {yield }}=\frac{3 \tau_{y}(H) L \pi}{4 h}\left(D^{2}-d^{2}\right) \Rightarrow \\
& \tau_{y}(H)=\frac{4 h f_{\text {yield }}}{L \pi\left(D^{2}-d^{2}\right)}
\end{aligned}
$$

in which $D$ and $d$ were the mount piston's outer and inner diameter respectively. $L, b$ and $h$ represented the mounts flow channel length, width and gap respectively. $\tau_{y}$ was the yield stress, which changes with magnetic field intensity. $H$ represented the magnetic field intensity, which changes with magnetic flux density. Figure 3 shows the MRF 122-EG magnetic characteristics.

Figure 4 shows the relation between magnetic field intensity, yield stress and magnetic flux density as a surface. The controller counted the desired yield stress in order to calculate

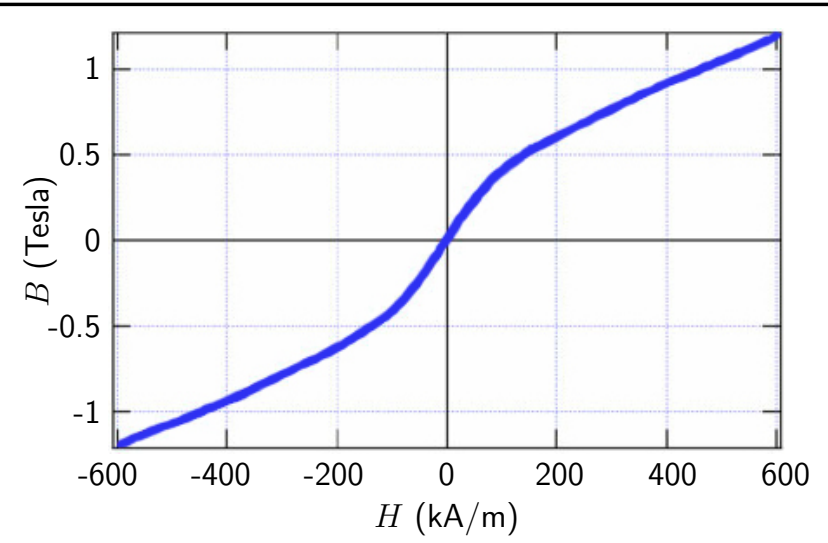

(a)

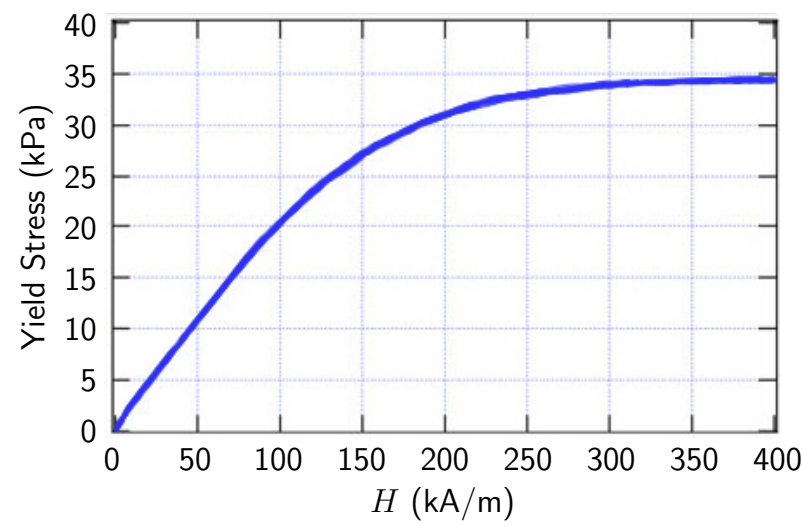

(b)

Figure 3. Magnetic characteristics of MRF a) yield stress b) magnetic flux density.

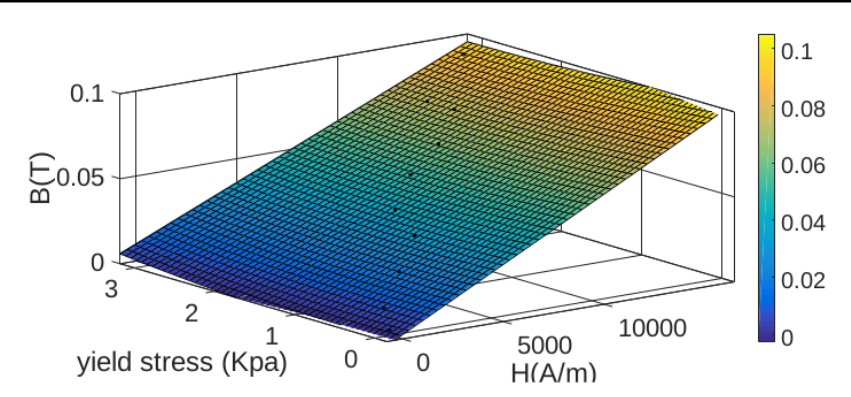

Figure 4. The MRF-122EG magnetic flux density related to Yield stress and magnetic field intensity.

the needed magnetic flux density. Only the operating point of the system is shown in the Fig. 4. The coil current related to magnetic flux density was obtained as:

$$
B=\frac{\mu N I}{2 \pi R} \Rightarrow I_{\text {controller }}=\frac{2 \pi R B}{\mu N}
$$

in which $N$ represented the number of coils. $I$ showed the coil current. $R$ represented the coil mean radius. $\mu$ was the fluid permeability constant. Because of the technical restrictions of the coil current, the maximum coil current is set to 3 amps.

\subsection{System Uncertainties}

Since the mass of the vehicle changes by mounting and dismounting the passengers, there is always an uncertainty in the mass of the vehicle. For the vehicle body mass, $40 \%$ uncertainty is considered which was represented as $M=\bar{M}(1+$ 


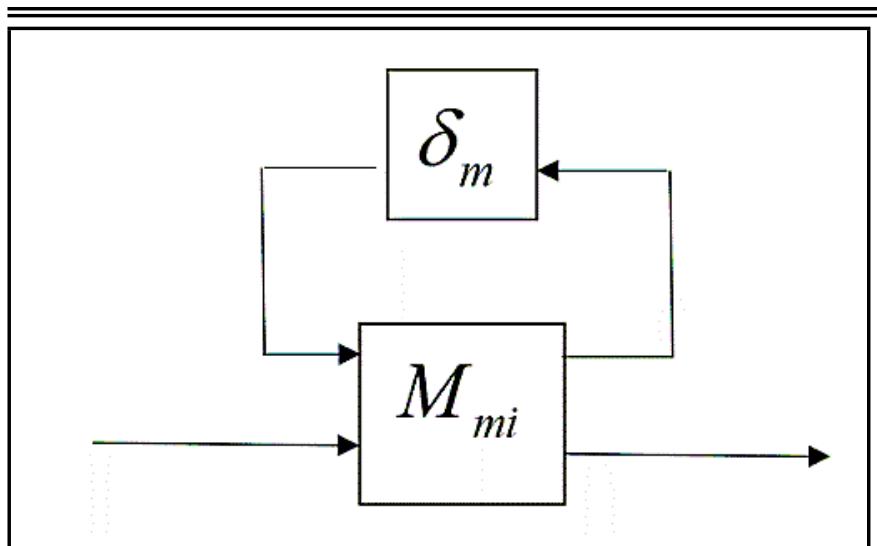

Figure 5. Mass uncertainty LFT. ${ }^{27}$

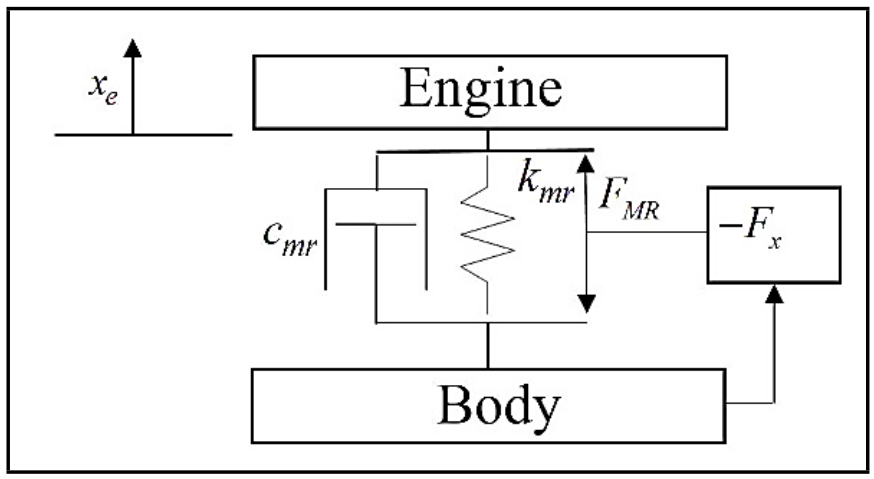

Figure 6. Engine mount controller.

$\left.p_{m} \delta_{m}\right) . \bar{M}$ was the nominal mass. $p_{m}$ represented the maximum amount of uncertainty, which was considered here as 0.4 . $\delta_{m}$ represented the percentage of uncertainty to the maximum uncertainty that was always $=1<\delta_{m}<1$. Given that $M$ was counted in the denominator, uncertainties were as follows: ${ }^{27}$

$$
\frac{1}{M}=\frac{1}{\bar{M}\left(1+P_{m} \delta_{m}\right)}=\frac{1}{\bar{M}}-\frac{P_{m}}{\bar{M}} \delta_{m}\left(1+P_{m} \delta_{m}\right)^{-1}
$$

The LFT of this block diagram is shown in Fig. $5 .^{27}$ In this system, the force was applied by the engine mount regarded as the control input and the system desired output was considered for the passengers' comfort.

\section{CONTROLLER DESIGN}

For the attenuation of vibration transmitted from the engine and road, engine mount parameters were changed over variable engine conditions. The controller changes the force generated by the MRF and engine mount parameter reaches to the desired value. Figure 6 shows the location of the controller in the system.

In order to design the controller for this system, a PID controller was designed via the Ziegler-Nichols tuning method. ${ }^{28}$ According to the ISO 8608, a road profile can be used as periodic vibration. By assuming a harmonic motion in the road, this unknown input could be represented by one wave or a sum of sinusoidal waves (Tudón-Martínez, S. Fergani, Martinez, Morales-Menendez, \& L. Dugard, 2015). The road profile was intended as follows:

$h_{r}=0.05 \sin (1.5 \pi t) \sin (0.15 \pi t)$

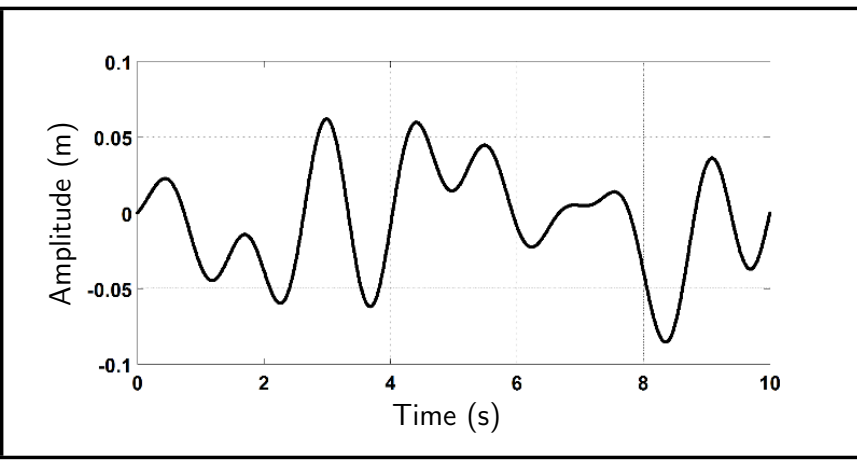

Figure 7. Road profile.

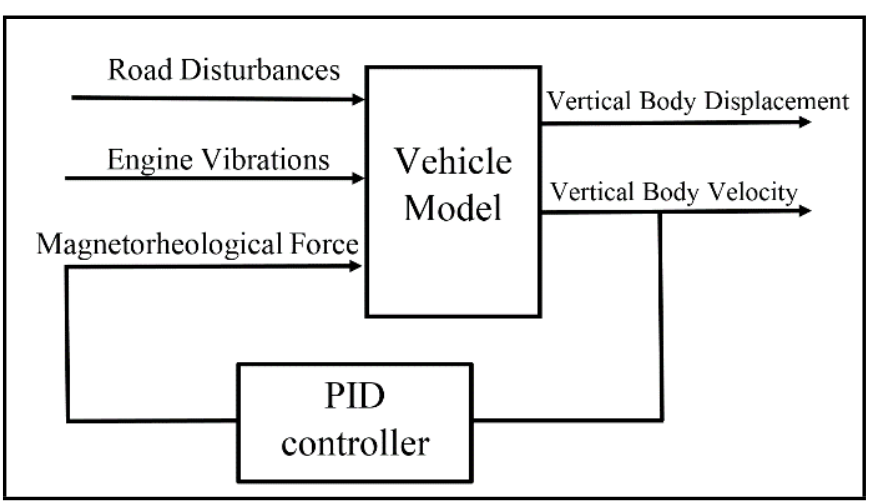

Figure 8. PID controller schematic diagram.

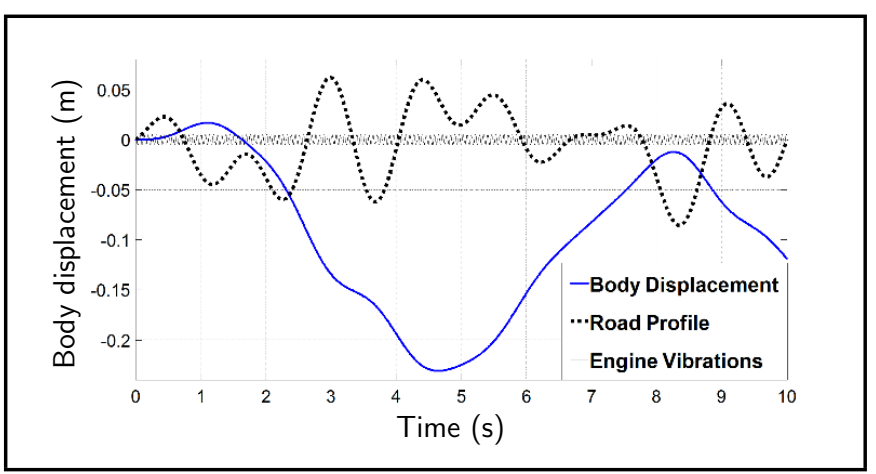

Figure 9. Body displacements with PID controllers.

$$
+0.05 \cos (0.6 \pi t) \sin (0.3 \pi t) \text {. }
$$

Figure 7 shows the road profile.

Figure 8 shows the systems diagram and its inputs and outputs. The system output and input were body velocity and MR force, respectively. As can be seen in the same figure, large uncertainties affected the controller and caused the inaccuracy and poor robustness of the control system.

\subsection{Robust Controller Design}

In this section, the robust $H_{\infty}$ controller was designed. Since the PID controller was unstable and was unable to damp vibrations caused by the engine and the road in the presence of uncertainties properly, a proper robust controller was used. The system state-space equations in the presence of disturbances are as follows: ${ }^{29}$

$$
\begin{aligned}
& \dot{x}=A x+B_{1} w+B_{2} u ; \\
& z=C_{1} x+D_{11} w+D_{12} u ; \\
& y=C_{2} x+D_{21} w+D_{22} u ;
\end{aligned}
$$


Table 1. Weighting functions for controller.

$$
\begin{array}{|c|}
\hline w_{1}=\frac{s}{s+1} \\
\hline w_{2}=\frac{1.24}{2.37} \frac{s+22.3}{s+31.7} \\
\hline
\end{array}
$$

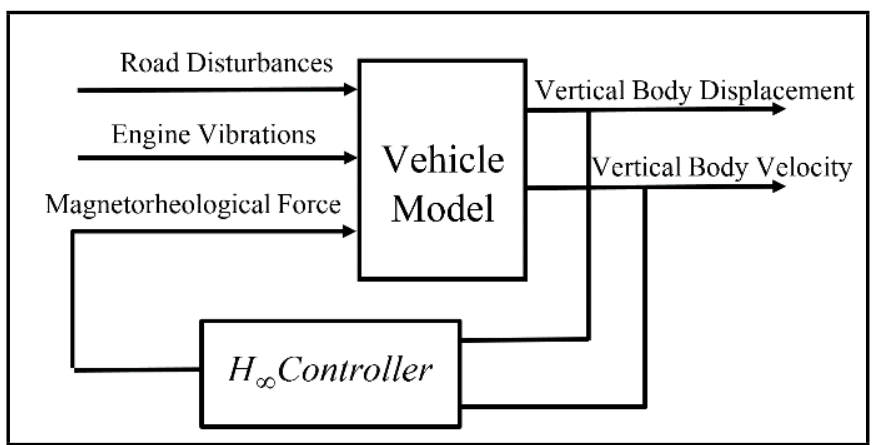

Figure 10. Controller schematic diagram.

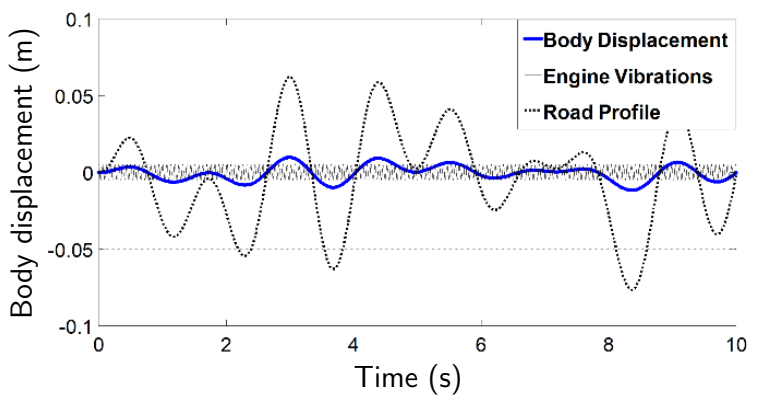

Figure 11. Body displacements with controllers.

where $x$ represented the system modes and $w$ represented the disturbing inputs, including road inputs for four wheels and engine vibrations. $u$ represented the smart fluid MR force input, $z$ represented the desirable output that was considered as the body acceleration $\left(\ddot{y}_{c}\right)$ here and $y$ was the measurable output that was considered as the body displacement and velocity $\left(y_{c}\right.$ and $\left.\dot{y}_{c}\right)$. By using model external disturbances and quantify the design objectives. The weighting functions for the $H_{\infty}$ controller is shown in the Table 1.

Figure 10 shows the system control diagram. For the controller design process, it was important for the output signal to have a smooth shape, prevent high frequencies, reduce phase shift and allow for more flexibility in the overall design. To do so the control law to MRF a fourth-order Butterworth low pass filter with a cutoff frequency of 3 times of the natural frequency was used..$^{30,31}$ This filter equation is as follows:

$$
\frac{0.018 S^{4}+0.074 S^{3}+0.111 S^{2}+0.074 S+0.018}{S^{4}+1.57 S^{3}+1.276 S^{2}+0.4844 S+0.0762} .
$$

Figure 11 shows body displacement in the presence of the engine vibrations and road-roughness.

As can be seen in the same figure, the body displacement has little magnitude in comparison with the road profile, a smooth shape and low frequency in comparison with the engine vibrations and the $H_{\infty}$ controller can attenuate the disturbances and uncertainties. Figure 12 shows the bode diagram of the designed $H_{\infty}$ and PID controllers in the $1-500 \mathrm{~Hz}$ bandwidth. The phase diagram for $H_{\infty}$ controllers has a minimum

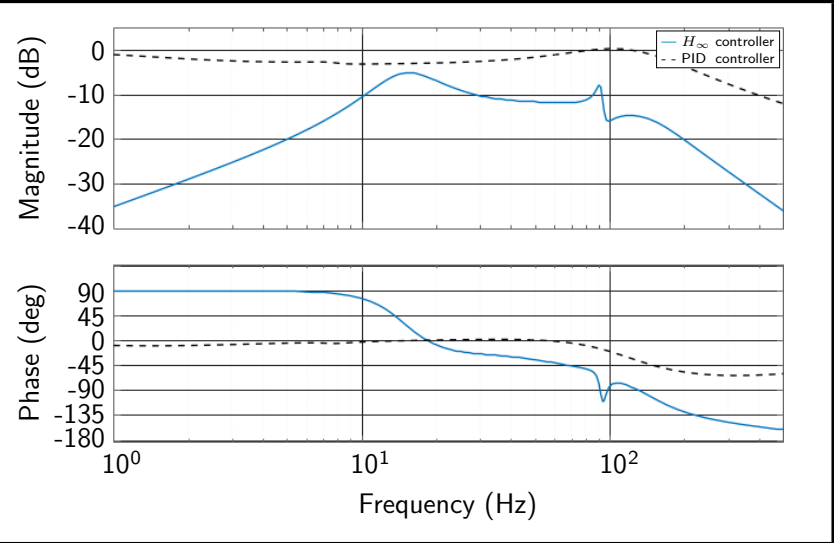

Figure 12. Comparison of Bode diagram of the and PID controller due to the body acceleration.

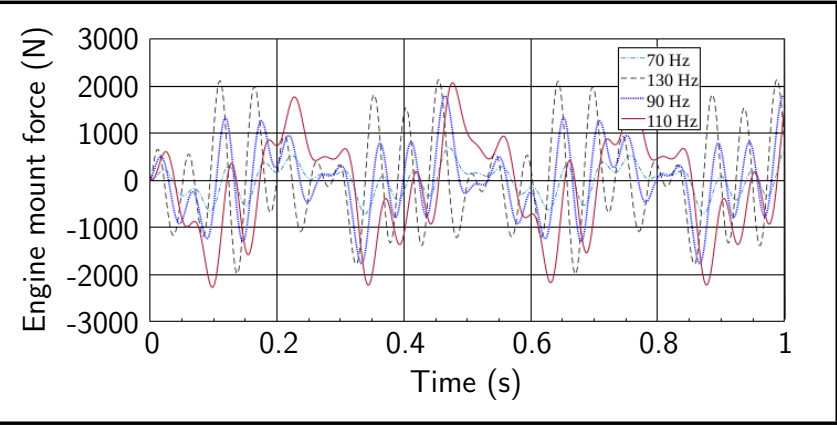

Figure 13. Engine mount force transmitted to the vehicle body in the different engine vibration frequencies.

of $50 \mathrm{~Hz}$ and a maximum of $100 \mathrm{~Hz}$. This indicates the maximum attenuation of designated controller in this frequency. On the other hand, the PID controller is saturated and cannot attenuate the disturbances in the engine frequency region (about $100 \mathrm{~Hz}$ ).

In addition, the designed controller reduced the transmitted engine vibration frequency significantly. Figure 13 depicts the force transmitted from the engine mount to the body for several engine excitation frequencies for the $H_{\infty}$ controller. These frequencies are 70,90,110 and $130 \mathrm{~Hz}$. This is the total force that was generated by both passive and active components of the engine mount. The Force magnitude is increased by increasing the engine vibration frequency. Figure 14 shows that the MRF produced force in the mentioned frequencies for the $H_{\infty}$ controller. This figure shows MRF can only damp energy and not supply it, thus a passivity established on the controller which supply current to the mount in dissipation phase. As the excitation frequencies intensify the MRF must produce more yielding stress to overcome the excitation force.

Figure 15 shows the bode diagram of the total transmitted force to the chassis for the $H_{\infty}$ and PID controller. The transmitted force has a maximum gain that is close to the engine excitation frequency $(100 \mathrm{~Hz})$ and the force phase is descending. The MRF force has a similar behavior and has two peaks in the road and engine vibration frequencies, which indicate that the designed controller can respond properly in the vibration. The PID controller cannot significantly reduce the transmitted force to the chassis. The $H_{\infty}$ controller is reduced about 3.6 times the transmitted force than the PID controller. 


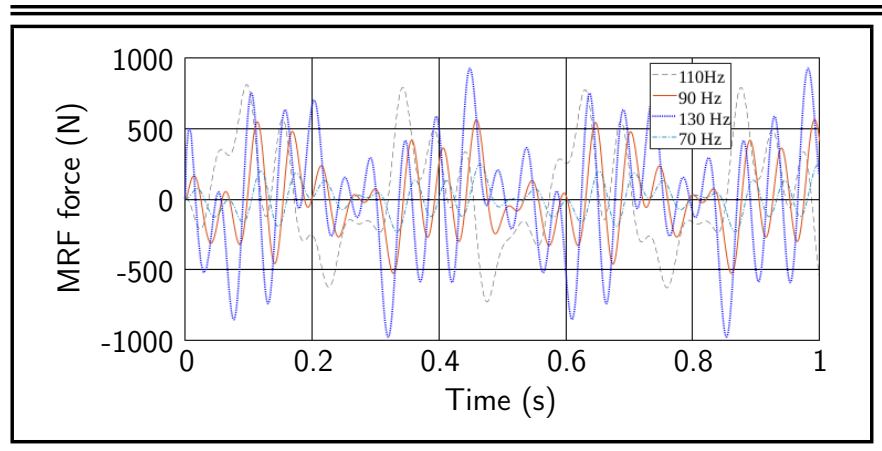

Figure 14. The MRF force in the engine mounts.

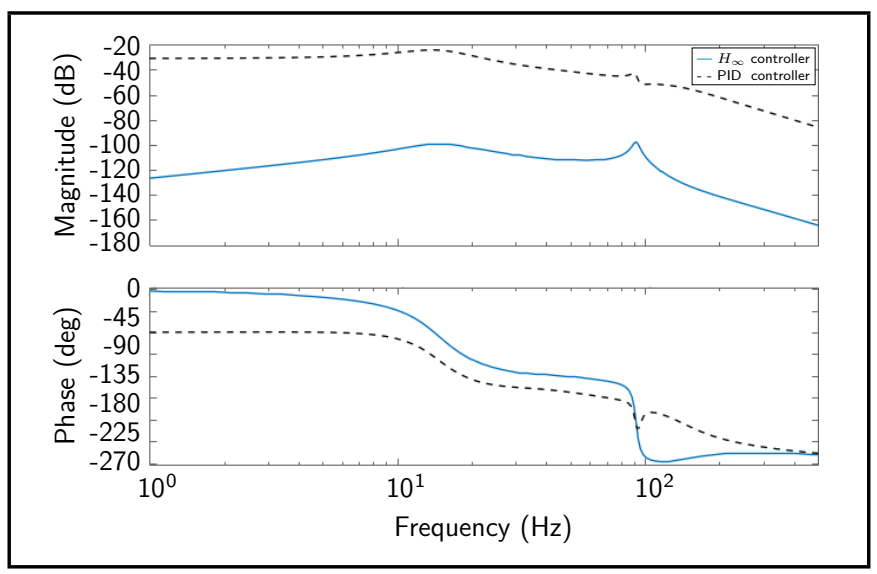

Figure 15. a) Magnitude diagram b) Phase diagram, of the transmitted force to the chassis for the and PID controller.

\section{CONCLUSIONS}

An $H_{\infty}$ robust controller is simulated and designed for the MRF semi-active engine mount. To do so, an 8-DOF is used which is imposed to a sinoside road profile and engine vibrations as disturbances. For reducing the effect of these disturbances, a semi-active engine mount with the help of the MRF is employed. First, a PID controller is designed. It is then confirmed that this controller cannot overcome the disturbances and uncertainties. Next, the $H_{\infty}$ controller is designed to minimize the vehicle body vibrations by changing the force generated by the MRF over the variable frequency range of disturbances. The results show that the designed controller can reduce over $50 \mathrm{~dB}$ of the magnitude of designed system in comparison with the passive engine mounts.

\section{REFERENCES}

1 Marzbanrad, J. \& Babalooei, M. Grazing bifurcations and chaos of ahydraulic engine mount International Journal of Automotive Engineering 6 (3), 2182-2190 (2016).

2 Ahn, Y. K., Ahmadian, M. \& Morishita, S. On the design and development of a Magnetorheological mount Journal of Vehicle System Dynamics 32 (2), 199-216 (1999).

3 Chung, J. U., Phu, D. X. \& Choi, S.-B. Optimization of new Magnetorheological fluid mount for vibration control of start/stop engine mode, presented at Active and Passive Smart Structures and Integrated Systems, San Diego, California, United States, 2015 (unpublished).

4 Ay, R., Golnaraghi, M. \& Khajepour, A. Investigation on a semi-active hydro mount using MR Fluid presented at
Proceedings of the NATO, Symposium on Active Control Technology for Enhanced Performance Operational Capabilities of Military Aircraft, Land Vehicles and Sea Vehicles, Braunschweig, Germany, May 2000 (unpublished).

5 Sarkar, C., Hirani, H. \& Sasane, A. Magnetorheological Smart Automotive Engine Mount International Journal of Current Engineering and Technology 21 (15), 1509-1516 (2015).

6 Barber, D. E. \& Carlson, J. D. Performance characteristics of prototype MR engine mounts containing LORD glycol MR fluids, presented at Proceedings of the 11th International Conference on Electrorheological Fluids and Magnetorheological Suspensions, Dresden, Germany, 2009 (unpublished). https://doi.org/10.1177/1045389X09351957

7 Nguyen, Q. H., Phu, D. X., Park, J. H., Choi, S. B. \& Kang, O. H. Development of high damping Magnetorheological mount for ship engines Journal of Applied Mechanics and Materials 336 (1), 338-346 (2013).

8 Ladipo, I. L., Fadly, J. \& Faris, W. F. Characterization of Magnetorheological elastomer (MRE) engine mounts Journal of Materials Today: Proceedings 3 (2), 411-418 (2016). https://doi.org/10.1016/j.matpr.2016.01.029

9 Choi, S.-B., Hong, S.-R., Sung, K.-G. \& Sohn, J.-W. Optimal control of structural vibrations using a mixedmodemagnetorheological fluid mount International Journal of Mechanical Sciences 50 (3), 559-568 (2008).

10 Marzbanrad, J., Poozesh, P. \& Damroodi, M. Improving vehicle ride comfort using an active and semi-active controller in a half-car model Journal of Vibration and Control 19 (9), 1357-1377 (2013). https://doi.org/10.1177/1077546312441814

11 Hemanth, K., Kumar, H. \& Gangadharan, K. Vertical dynamic analysis of a quarter car suspension system with MR damper Journal of the Brazilian Society of Mechanical Sciences and Engineering, 41-51 (2017). https://doi.org/10.1007/s40430-015-0481-7

12 Choi, S. B., Li, W., Yu, M., Du, H., Fu, J., \& Do, P. X. State of the art of control schemes for smart systems featuring Magnetorheological materials Journal of Smart Materials and Structures 25 (4), 043001 (2016).

13 Marzbanrad, J. \& Zahabi, N. H inf active control of a vehicle suspension system exited by harmonic and random roads Journal of Mechanics and Mechanical Engineering 21 (1), 171-180 (2017).

14 Wei, C., Zhang, K., Cai, Y., Wang, Z. \& Yu, W. A new method of static output-feedback $H_{\infty}$ controller design for 5 DOF vehicle active suspension system Journal of the Brazilian Society of Mechanical Sciences and Engineering 40 (3), 1678-5878 (2018). https://doi.org/10.1007/s40430018-1054-3

15 Hemanth, K., Kumar, H. \& Gangadharan, K. Dynamic Analysis of Half Car Model with MR Damper as SemiActive Suspension Element International Journal of Acoustics and Vibration 23 (2), 138-146 (2018). 
16 Fakhari, V., Ohadi, A. \& Talebi, H. A. A robust adaptive control scheme for an active mount using a dynamic engine model Journal of Vibration and Control 21 (11), 22232245 (2013). https://doi.org/10.1177/1077546313506927

17 Wang, L. \& Melnik, R. V. Nonlinear dynamics of shape memory alloy oscillators in tuning structural vibration frequencies Jouranl of Mechatronics 22 (8), 1085-1096 (2012). https://doi.org/10.1016/j.mechatronics.2012.09.004

${ }^{18}$ Han, Y.-M., Choi, S.-M., Choi, S.-B. \& Lee, H.-G. Design and control of a hybrid mount featuring a Magnetorheological fluid and a piezostack Jouranl of Smart Materials and Structures 20 (7), 075019 (2011).

19 Fakhari, V. \& Ohadi, a. A. Robust control of automotive engine using active engine mount Journal of Vibration and Control 7 (19), 1024-1050 (2012). https://doi.org/10.1177/1077546312439590

20 Winberg, M., Johansson, S., Håkansson, L., Claesson, I. \& Lagö, T. L. Active Vibration Isolation in Ships: A PreAnalysis of Sound and Vibration Problems International Journal of Acoustics and Vibratio 10 (4), 175-196 (2005).

${ }^{21}$ Barber, D. E. \& Carlson, J. D. Performance characteristics of prototype MR engine mounts containing glycol MR fluids Journal of Intelligent Material Systems and Structures 21 (15), 1509-1516 (2010).

${ }^{22}$ Hong, S. R., Choi, S. B., Jung, W. J., Ham, I. B. \& Kim, D. K. Vibration control of an ER mount subjected to high static loads Journal of Sound and Vibration 242 (4), 740748 (2001). https://doi.org/ 10.1006/jsvi.2000.3358

${ }^{23}$ Li, Y., Li, J., Li, W. \& Samali, B. Development and characterization of a Magnetorheological elastomer based adaptive seismic isolator Journal of Smart Materials and Structures 22 (3), 035005 (2013).

${ }^{24}$ Elahinia, M., Ciocanel, C. \& Wang, S. MR-and ERbased semiactive engine mounts: a review Journal of Smart Materials Research 2013 (1), 831017 (2013). http://doi.org/10.1155/2013/831017

25 Rasekhipour, Y. \& A.Ohadi A study on performance of simplified vehicle models in optimization of hydraulic engine mounts in comparison with full vehicle International Journal of Automotive Engineering 1 (2) (2011).

${ }^{26}$ Huang, S.-C. Some discussions of MR engine mount on vibration attenuation and force transmission, presented at The 21st International Congress on Sound and Vibration, Beijing/China, 2014 (unpublished).

${ }^{27}$ Gu, D.-W., Petkov, P. H. \& Konstantinov, M. M., Robust control design with MATLAB (Springer-Verlag, London, 2005).

28 Ikhlef, A., Kihel, M., Boukhezzar, B., Mansouri, N. \& Hobar, F., Online PID control of tank level system, presented at 2016 IEEE Global Engineering Education Conference (EDUCON), Abu Dhabi, 2016 (unpublished). https://doi.org/10.1191/0142331203tm0098oa
${ }^{29}$ Olsson, C. Active automotive engine vibration isolation using feedback control Journal of Sound and Vibration 294 (1), 162-176 (2005). https://doi.org/10.1016/j.jsv.2005.10.022

${ }^{30}$ Freeborn, T. J., Elwakil, A. S. \& Maundy, B. Approximated fractional order inverse Chebyshev lowpass filters Journal of Circuits, Systems, and Signal Processing 35 (6), 19731982 (2016). https://doi.org/10.1007/s00034-015-0222-2

31 Sadiq, A. A., Othman, N. B., Jamil, M. A., Youseffi, M., Denyer, M., Zakaria, W. W., \& Tomari, M. M. Fourth-Order Butterworth Active Bandpass Filter Design for SingleSided Magnetic Particle Imaging Scanner Journal of Telecommunication, Electronic and Computer Engineering (JTEC) 10 (17), 17-21 (2018).

${ }^{32}$ Hong, S.-R. \& Choi, S.-B. Vibration Control of a Structural System Using Magneto-Rheological Fluid Mount Journal of Intelligent Material Systems and Structures 16 (11), 931936 (2005). https://doi.org/10.1177/1045389X05053917

${ }^{33}$ Marzbanrad, J. \& Zahabi, N., H inf Active Control of a Vehicle Suspension System Exited by. Mechanics and Mechanical Engineering 21 (1), 171-180 (2017). doi:10.1007/s40430-018-1054-3

34 Marzbanrad, J., Poozesh, P. \& Damroodi, M. Improving vehicle ride comfort using an active and semi-active controller in a half-car model Journal of Vibration and Control, 13571377 (2013). https://doi.org/10.1177/1077546312441814

\section{APPENDIX A}

The parameters in the Eqs. (1)-(4) is listed below:

Table 2. Vehicle dynamic parameters

\begin{tabular}{||l|l|}
\hline Parameter name & amount \\
\hline Engine mass $\left(M_{e}\right)$ & $215 \mathrm{~kg}$ \\
\hline Front unsprung mass $\left(M_{u 1}, M_{u 4}\right)$ & $29.5 \mathrm{~kg}$ \\
\hline Rear unsprung mass $\left(M_{u 2}, M_{u 3}\right)$ & $27.5 \mathrm{~kg}$ \\
\hline Front suspension damping $\left(c_{s 1}, c_{s 4}\right)$ & $3200 \frac{\mathrm{Ns}}{\mathrm{m}}$ \\
\hline Rear suspension damping $\left(c_{s 2}, c_{s 3}\right)$ & $1700 \frac{\mathrm{Ns}}{\mathrm{m}}$ \\
\hline Front suspension stiffness $\left(K_{s 1}, K_{s 4}\right)$ & $20580 \frac{\mathrm{N}}{\mathrm{m}}$ \\
\hline Rear suspension damping $\left(K_{s 2}, K_{s 3}\right)$ & $19600 \frac{\mathrm{N}}{\mathrm{m}}$ \\
\hline Sprung mass $\left(M_{s}\right)$ & $868 \mathrm{~kg}$ \\
\hline Inertia about y axis $\left(I_{s y}\right)$ & $235 \mathrm{~kg} \mathrm{~m}{ }^{2}$ \\
\hline e Inertia about $\mathrm{z}$ axis $\left(I_{s} z\right)$ & $920 \mathrm{~kg} \mathrm{~m}$ \\
\hline Tire stiffness $\left(K_{t 1} \ldots K_{t 4}\right)$ & $2 \times 10^{5} \frac{\mathrm{N}}{\mathrm{m}}$ \\
\hline Position of mount in y direction $\left(y_{m}\right)$ & $-0.31 \mathrm{~m}$ \\
\hline Position of mount in z direction $\left(z_{m}\right)$ & $0.13 \mathrm{~m}$ \\
\hline Stiffness of rubber part of mount $\left(K_{m r}\right)$ & $2.23 \times 10^{5} \frac{\mathrm{N}}{\mathrm{m}}$ \\
\hline Damping of rubber part of mount $\left(C_{m r}\right)$ & $98 \frac{\mathrm{Ns}}{\mathrm{m}}$ \\
\hline \hline
\end{tabular}

